\title{
The Effect of Rail Fastening System Modifications on Tram Traffic Noise and Vibration
}

\author{
Stjepan Lakušić, Ivo Haladin, and Maja Ahac \\ Department for Transportation Engineering, Faculty of Civil Engineering, University of Zagreb, Fra Andrije Kačića Miošića 26, \\ 1000 Zagreb, Croatia
}

Correspondence should be addressed to Ivo Haladin; ihaladin@grad.hr

Received 26 December 2015; Accepted 7 March 2016

Academic Editor: Rafał Burdzik

Copyright (C) 2016 Stjepan Lakušić et al. This is an open access article distributed under the Creative Commons Attribution License, which permits unrestricted use, distribution, and reproduction in any medium, provided the original work is properly cited.

\begin{abstract}
Tram system is a backbone of public transportation in the City of Zagreb. In the last decade, its fleet has been renewed by 142 new low-floor trams. Shortly after their introduction, it was observed that they have a negative impact on the exploitation behavior of tram infrastructure, primarily on the durability of rail fastening systems. Because of that, it was decided to modify existing rail fastening systems to the new track exploitation conditions. When the (re)construction of tram infrastructure is carried out by applying new systems and technologies, it is necessary to take into account their impact on the future propagation of noise and vibration in the environment. This paper gives a short overview of the characteristics of the two newly developed rail fastening systems for Zagreb tram tracks, their application in construction of experimental track section, and performance and comparison of noise and vibration measurements results. Measured data on track vibrations and noise occurring during passage of the tram vehicles is analyzed in terms of track decay rates and equivalent noise levels of passing referent vehicle. Vibroacoustic performance of new fastening systems is evaluated and compared to referent fastening system, in order to investigate their ability to absorb vibration energy induced by tram operation and to reduce noise emission.
\end{abstract}

\section{Introduction}

Tram system is a backbone of public transportation in the City of Zagreb. It consists of more than $116 \mathrm{~km}$ of tram tracks, used daily by 180 tram vehicles. In the last decade, systems manager Zagreb Electric Tram (ZET) Ltd. has renewed its fleet by purchasing 142 new low-floor trams TMK 2200, produced by CROTRAM consortium. Another 28 low-floor trams have since then been commissioned from the same consortium. Shortly after the introduction of new low-floor trams, it was observed that this fleet modernization has increased exploitation demands on other components of tram infrastructure, that is, the power supply system and track superstructure.

Regarding the effects on the track superstructure, the main consequences of the new vehicles introduction have been increase in loading forces, altered load distribution, and altered geometry of wheel and rail contact surface. This is because new low-floor trams are heavier (on average, up to $60 \%$ ), with differently located center of gravity and different wheel profiles compared to the old ones [1]. These changes in tram track exploitation parameters have caused more frequent rail fastening system failures, which reflected in the increased rail wear and accelerated track geometry degradation. In event of such mayor rolling stock renewal, track structure parameters have to be evaluated $[2,3]$ and modified. Because of that, ZET Ltd. has decided to adjust existing rail fastening systems to the new track exploitation conditions. This was done through technical collaboration with the University of Zagreb Faculty of Civil Engineering, considering the vast experience and expertise in design and supervision of railway and tram track structures. Through similar cooperation, there have been several successful design changes to basic tram track superstructures in order to achieve better vibroacoustic performance and durability, that is, in tight curves [4], at busy level crossings [5] and tracks constructed over underground garage structures [6]. Apart from acoustic properties, major concerns in designing a suitable fastening system are vibrations and impact loads due to running surface discontinuities, which occur at switches and crossings $[7,8]$. 
When developing any new rail track system, calculations, modeling, and testing of new systems individual components material, and system as a whole, are not sufficient for its direct application in everyday engineering practice. It was therefore decided to conduct monitoring of new fastening systems exploitation behavior. This was done by construction of the test track section with built-in new fastening systems [9]. On it, the following continuous and periodic measurements were made:

(i) Visual inspections of track superstructure.

(ii) Measurements of track and weld geometry.

(iii) Measurements of stresses and strains of tracks reinforced concrete foundation slab.

(iv) Measurements of the tracks dynamic properties (i.e., vibration damping).

In urban areas, due to the proximity between the tram tracks and the residential buildings, from the perspective of the surrounding residents but also the tram users, the problem of rail traffic noise and vibrations is particularly pronounced. Therefore, if the (re)construction of tram infrastructure is carried out by applying new systems and technologies, it is necessary to take into account their impact on the future propagation of noise and vibration in the environment. This paper gives a short overview of the characteristics of the two newly developed rail fastening systems for Zagreb tram tracks, their application in construction of the test track section, and performance and comparison of noise and vibration measurements results. Data on rail vibrations occurring during passage of the tram vehicles will demonstrate the ability of the track experimental constructions to absorb vibrations and thus prevent their propagation in the environment. The greater is the ability of the rail fastening systems to effectively attenuate rail vibrations induced by passing tram vehicle, the lesser will be the propagation of noise and vibration in the environment.

\section{Development and Characteristics of New Rail Fastening Systems}

The primary role of the rail fastening system is positioning and fixing of the rails and transferring the vehicle load from the rails to the track substructure. Generally, the type and characteristics of fastening system are chosen depending on the required elasticity of the track, planned load, and type of rail. On major part of Zagreb tram tracks, grooved rails are discreetly laid on the levelling layer, made out of micro synthetic concrete, and built on reinforced concrete slab. The distance between levelling layer supports is one meter in the tram rolling direction. Rails are fixed to these blocks by several different types of fastening systems [7], mostly by

(i) direct elastic fastening system ZG 3/2 (Figure 1(a)) with $140 \mathrm{MN} / \mathrm{m}$ stiffness, developed during the $1980 \mathrm{~s}$ and still used on about $20 \%$ of network; (ii) indirect elastic fastening system with decreased stiffness PPE (Figure 1(b)) with $50 \mathrm{MN} / \mathrm{m}$ stiffness, developed during the 1990s in order to increase tram track life span and used on about $10 \%$ of network;

(iii) indirect elastic fastening system DEPP (Figure 1(c)) with $40 \mathrm{MN} / \mathrm{m}$ stiffness, developed in order to solve all the essential flaws of its predecessors and used on about $50 \%$ of network.

By reducing the fastening systems stiffness, vehicle load is transferred to greater number of bearings (supports). This reduces the strain of individual bearing and the speed of load increment and prolongs the life of both the bearings and rails. Reducing the stiffness also lowers the rails frequency, which reflects positively on the overall construction of the track and reduces tram traffic noise and vibration. However, the abovementioned indirect elastic fastening systems reflect state of the art and the demands on the exploitation behavior of the tracks from the beginning of the 1990s, which do not meet today's highly complex exploitation requirements on Zagreb's tram tracks:

(i) large tram traffic volume (individual sections of Zagreb's tram tracks that have a traffic volume of up to 15 million gross tons per year),

(ii) high vehicle passing frequency (vehicle frequency which is less than 90 seconds between vehicles on individual sections),

(iii) high wheel loads on low-floor trams (more than 3.5 tons per wheel),

(iv) strict tolerances regarding the narrow, $1000 \mathrm{~mm}$ gauge, track geometry.

Based on the above requirements, during the last few years the faculty has developed five different concepts for new fastening systems. Two of them, with working titles 21-CTT (Classic Tram Track) (the name was chosen because the structure of the system is an upgrade of the existing indirect elastic systems) and 21-STT (Slab Tram Track), were chosen for further development. Their characteristics, production requirements, and installation methods best match previous experiences in the construction and maintenance of tram tracks in Zagreb.

21-CTT system (Figure 2(a)) places the rails discreetly on the levelling layer, made out of micro synthetic concrete, built on reinforced concrete slab (Figure 3 ). The distance between supports is one meter in the tram rolling direction. The rail foot is supported by neoprene pads placed on ribbed steel plate, laid on the levelling layer. To ensure the durability of individual components and ease the installation during construction and dismantling during the track reconstruction, the underside of the ribbed steel plate is fitted, by vulcanization process, with elastic pad. Vulcanization process enabled production of a compact element electrically isolated from other components (anchors) but also provided additional elasticity of the whole fastening system.

21-STT system (Figure 2(b)) represents a completely new solution for tram tracks superstructure construction in Croatia. Its main advantage over the previous systems is 


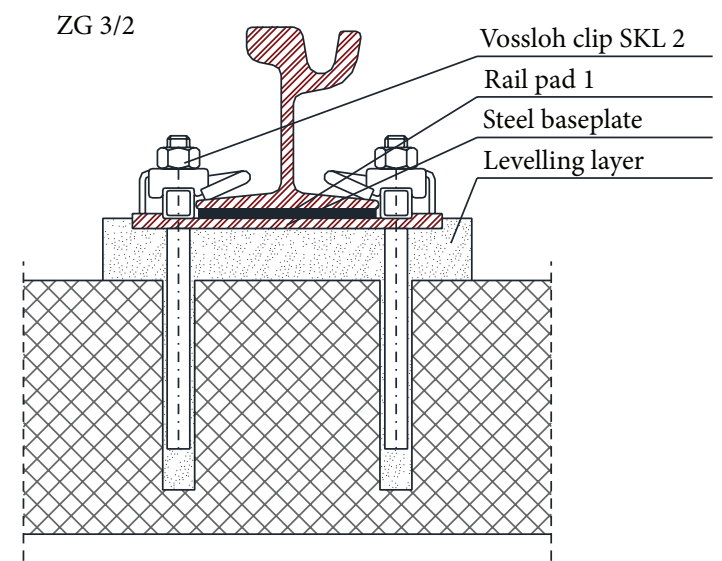

(a) ZG 3/2 fastening system

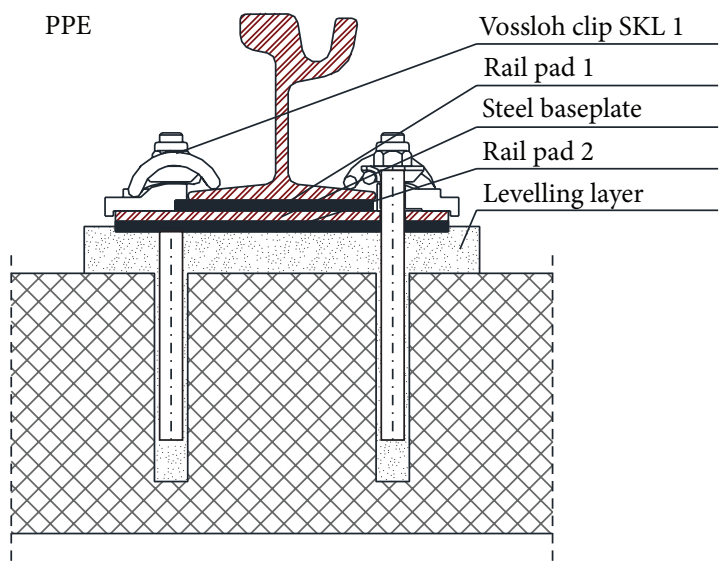

(b) PPE fastening system

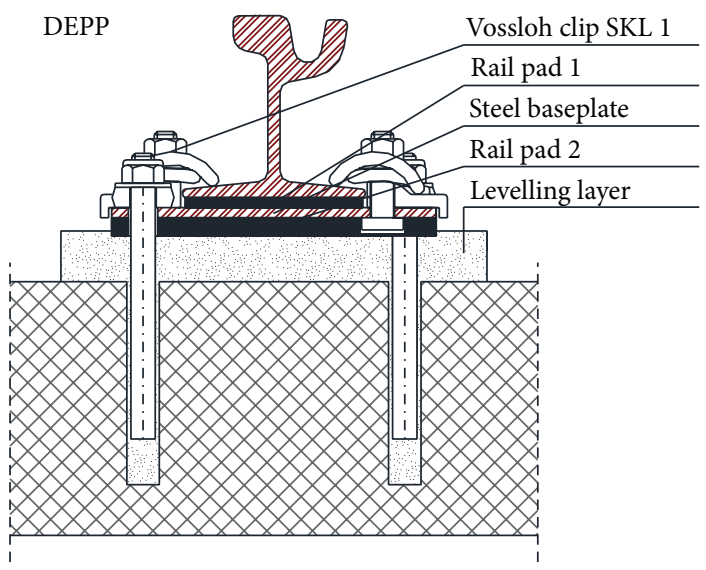

(c) DEPP fastening system

FIGURE 1: Schematic cross sections of rail discrete bearings with ZG-3/2, PPE, and DEPP fastening systems.

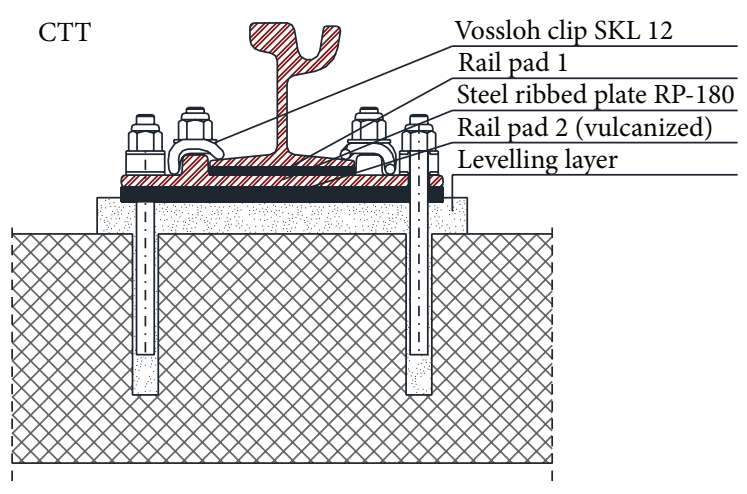

(a) 21-CTT fastening system

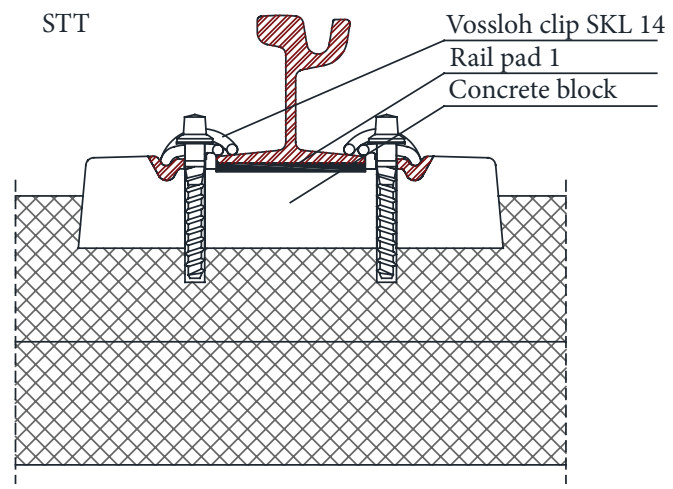

(b) 21-STT fastening system

FIGURE 2: Schematic cross sections of rail discrete bearings with 21-CTT and 21-STT fastening systems.

that the levelling layer (which is quite difficult to construct) is replaced by two block precast concrete sleepers laid on reinforced concrete base slab, one meter apart (Figure 4). Upper reinforced concrete slab is constructed after track horizontal and vertical alignment adjustment. This is a direct elastic fastening system, with one elastic pad between the rail foot and block sleeper.

\section{Construction of the Test Track Section}

In order to determine exploitation characteristics of newly developed tram track fastening systems and get detailed insight into the behavior of its elements and the track structure as a whole, in the spring of 2014 a plan and program of test track section construction and monitoring in Savska 


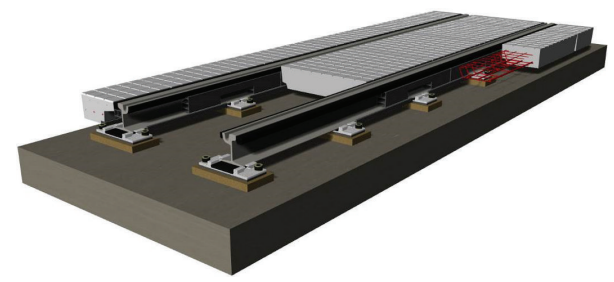

FIGURE 3: Design model of tram track structure with 21-CTT fastening system.

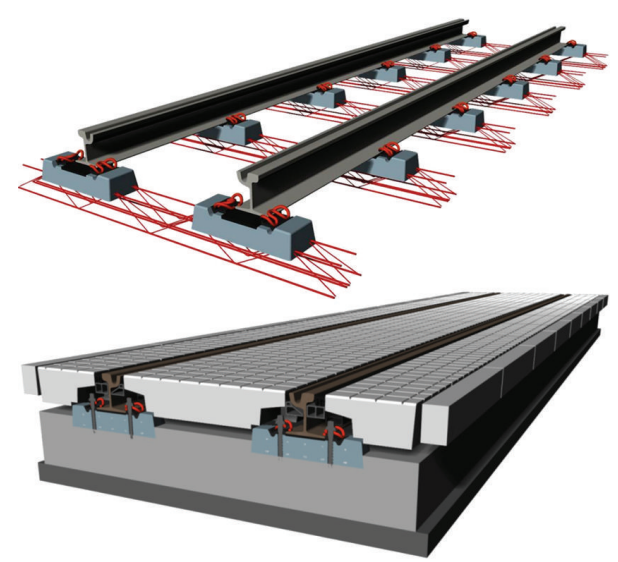

FIGURE 4: Design model of tram track structure with 21-STT fastening system.

Street was adopted. The said track section was, according to track maintenance program, planned for reconstruction due to its deterioration. For the purpose of the research, the section was divided into three subsections. The first subsection is designed as a reference and reconstructed using the standard PPE fastening system. The second reconstructed subsection is fitted with a 21-CTT fastening system, and the third is reconstructed as 21-STT system (Figure 5).

Figures 6-8 show a brief photodocumentation of entire test track section construction. It included the following phases: demolition of existing track (Figure 6(a)), construction of the new mechanically compacted base layer (Figure 6(b)), construction of new reinforced concrete slab (Figure 6(c)), construction of the bearings with fastenings and rail mounting (Figure 7), embedding the tracks with prefabricated concrete plates (Figure $8(a)$ ) and sealing the expansion joints between the rails and the cover plate (Figure $8(\mathrm{~b})$ ), completed tram track, and being paved with prefabricated concrete plates, in service (Figure 9).

In the phase of construction, all three test track subsections were fitted with elements necessary to perform continuous and periodic measurements during track exploitation. For the purpose of measurements of stresses and strains of tracks reinforced concrete foundation slab, relative deformation (strain) sensors have been built in the concrete slab (Figure 6(c)). For the purpose of visual inspection of bearings and fastening systems and also for easy access and installation of accelerometers for rail vibration measurements, revision shafts have been built in prefabricated concrete plates.

\section{Noise and Vibration Measurements}

The main sources of noise and vibrations on rail tracks are the propulsion noise of locomotives and power cars coming from the engines, aerodynamic noise that occurs at very high train speeds, and wheel/rail interaction. The latter is the main noise and vibrations source in urban rail traffic, where the vehicle speed is not high enough to take into account aerodynamic noise [12].

When vehicles run on the tracks, their weight coupled with the dynamic forces resulting from running surface irregularities causes oscillations, that is, vibrations of rail vehicles and whole track construction. At high frequencies $(100-5000 \mathrm{~Hz})$, the energy of these vibrations is propagated through the air in the form of sound waves (noise). Lower frequency vibrations $(0-100 \mathrm{~Hz}$ ) are transmitted from rails to the lower parts of track structure and surrounding soil [13].

The contribution of noise emitted by rail vibration is a significant component of rolling noise up to $5 \mathrm{kHz}$ [14]. One major factor affecting track noise performance has been identified to be the attenuation rate of vibration on the rail as a function of the distance from the excitation point [15], referred to as track decay rate measured in $\mathrm{dB} / \mathrm{m}$. Namely, the longer the section of the rail that vibrates, more noise is emitted to the environment. If the rail vibrations attenuate rapidly along the rail, and high decay rate is achieved, less noise is emitted. This parameter is often used to describe vibroacoustic behavior of a railway track in order to

(i) assess the track side influence on noise level emitted by rail vehicle during pass-by test according to EN ISO 3095 [11],

(ii) determine dynamic parameters for separation of noise sources [16],

(iii) determine total efective roughness of a vehicle on a test track [17],

(iv) evaluate applied vibration attenuation devices (i.e., rail dampers) [18],

(v) tune and adjust rail dampers [19, 20].

On test track in Savska Street, noise and vibrations have been measured under tram traffic load. Measurements have been conducted at all three test subsections under referent vehicle, that is, tram type TMK 2200 (Figure 11), pass-by. Passby noise and vibration measurements have been conducted under constant speed of $30 \mathrm{~km} / \mathrm{h}$ of an empty tram, garage number TMK 2266 (Figure 13). This measurement setup has been used in order to establish unified excitation of noise and vibrations during the experiments and to measure track side contribution to equivalent noise levels. Namely, by using unloaded tram with the known characteristics given in Figure 13, under constant speed, throttle condition, wheel roughness condition, and so forth, it was presumed that difference in measured equivalent noise levels on different test track subsections is solely related to track vibroacoustic properties. The measurements were performed during the night hours, in order to eliminate the influence of surrounding road traffic noise, which makes a significant contribution to overall noise levels during daytime. 


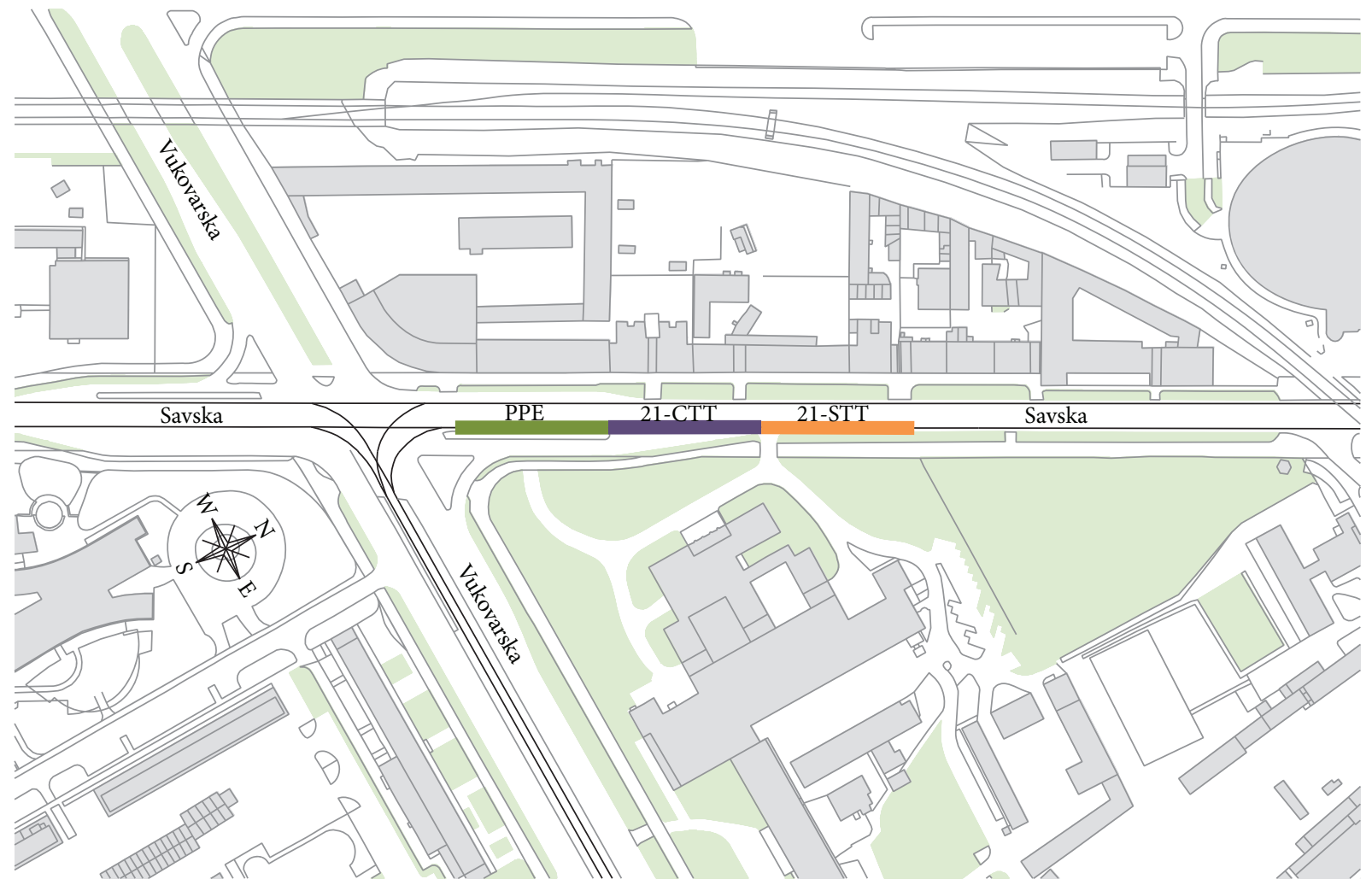

(a) Test track section layout

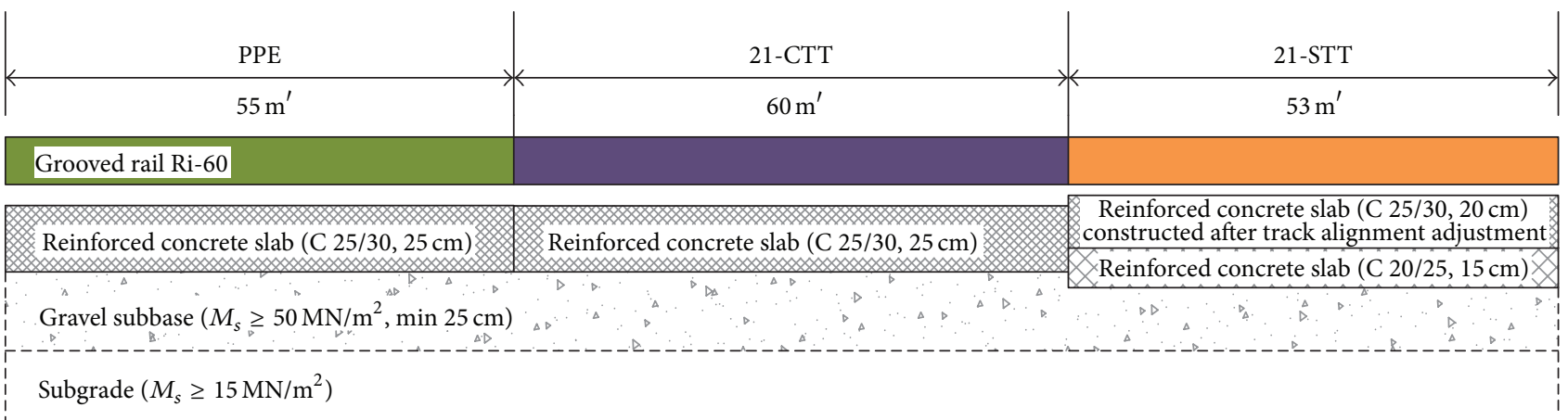

(b) Test track subsections longitudinal section

FIgURE 5: Test track section in Savska Street.

Accelerometers have been positioned inside each test track subsection respecting the minimum distance of $5 \mathrm{~m}$ from rail welds, $40 \mathrm{~m}$ from rail expansion joints according to [17]. Based on previous research on these tram track sections [9], it has been established that the substantial length for both vibration and noise measurements is twice the distance from microphone and accelerometer to each side along the track. This adds up to $10 \mathrm{~m}$ long track measurement sections (5 to each side of the microphone and accelerometer position) on each investigated tram track subsection structure.

In lack of regulations related to noise levels of passing tram vehicles as well as vibrations of tram track responsible for noise generation, European standards suggested in Comission Regulation (EU) number 1304/2014, on the technical specification for interoperability relating to the subsystem "rolling stock-noise" [21], have been used. Namely, for type pass-by noise measurements the regulation prescribes use of EN ISO 3095:2013 standard [11]. It can be adapted to noise measurements of passing tram vehicles with certain deviations related to tram speed and distance of microphone from the track axis. The mentioned standard prescribes measurement of two railway track parameters in order to evaluate the track side contribution to overall noise levels measured in a typical pass-by test. These standards are related to rail surface roughness, HRN EN 15610:2009 [22], and to track dynamic properties, HRN EN 15461:2011 [10]. Rail surface roughness has not been measured because newly constructed experimental track section had the same rails 

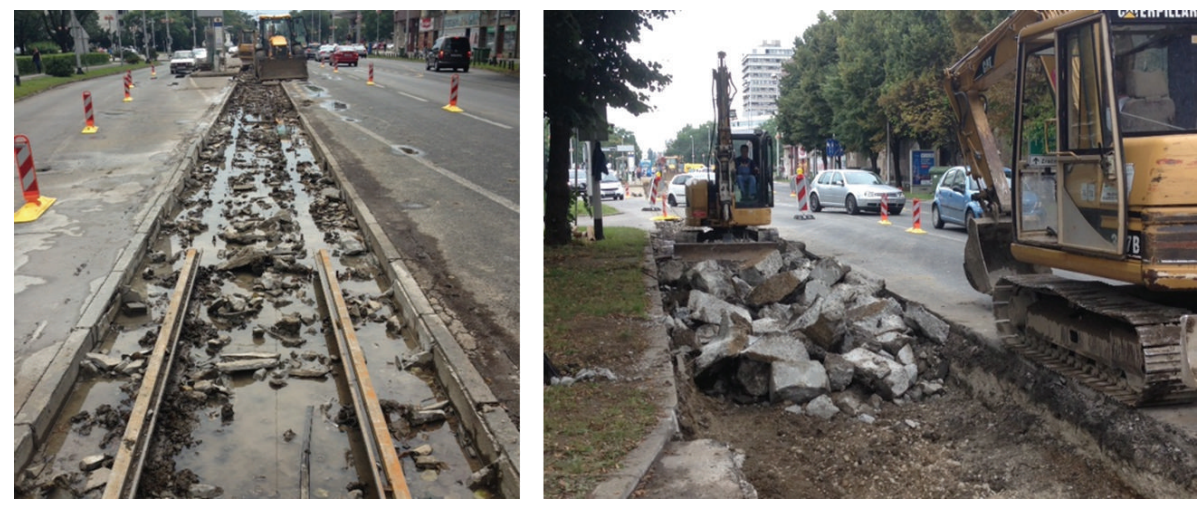

(a) Demolition of existing tram track
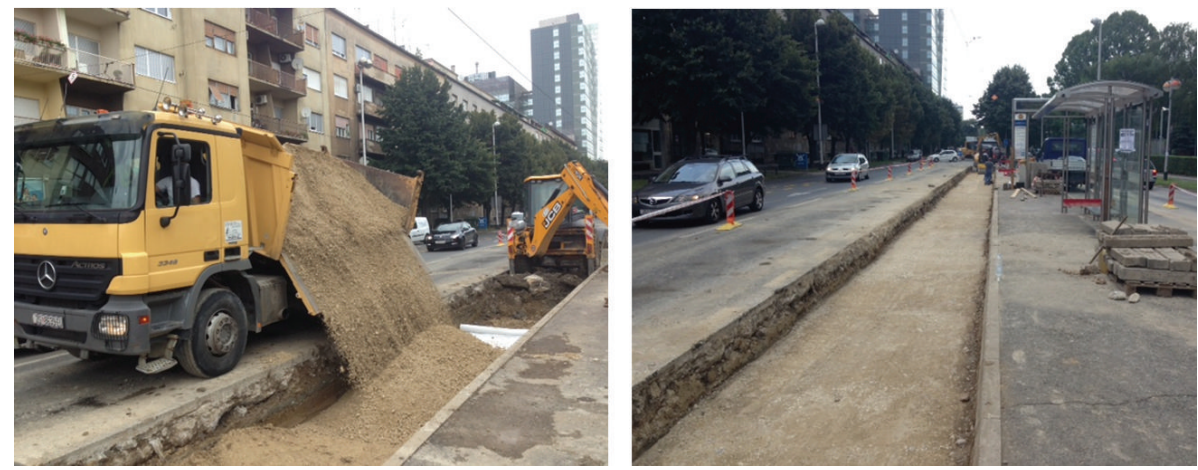

(b) Construction of the new mechanically compacted base layer
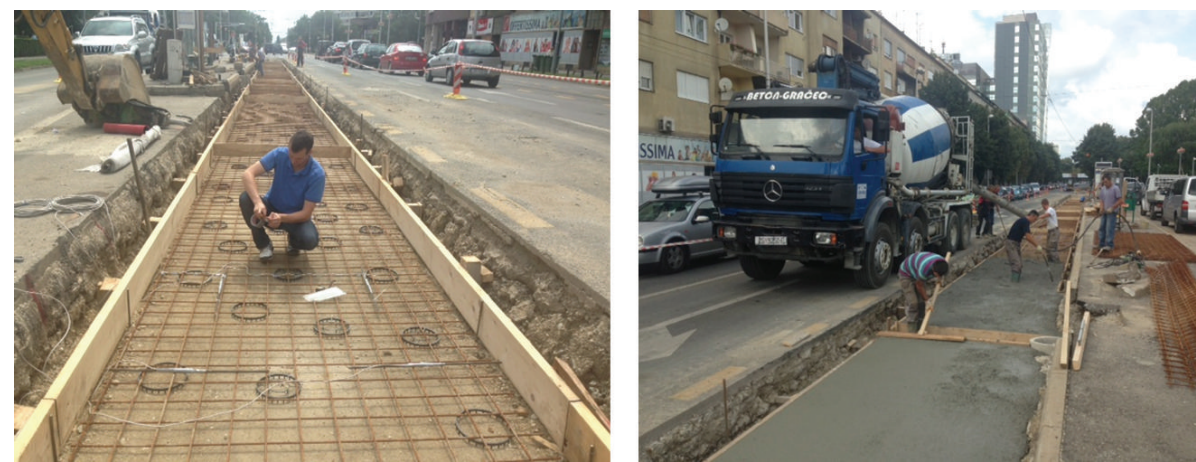

(c) Fitting strain gauges to slab reinforcement (left), casting of new reinforced concrete slab (right)

FIGURE 6: Tram track substructure construction on test track section.

installed along all three subsections and they are exposed to same operational conditions; hence, the rails are assumed to be equally smooth/rough in the time on the conducted measurements.

The parameter that describes the attenuation of the track vibration amplitude (Figure 10) is referred to as the track decay rate (TDR). Track decay rates in vertical and lateral direction with respect to rail cross section are determined according to [10] by using instrumented hammer as excitation force. Decay rates can alternatively be measured using vehicles pass-by and recording time signal of vibrations in vertical and lateral direction. This approach has been extensively investigated on standard rail track structures and discribed in [23-27]. It has been proposed for inclusion in future version of European standards as an alternative method of determining track decay rate and is currently published as a CEN Technical Report [17]. This approach has been selected for conducting decay rate values of test sections due to several practical reasons that include

(i) shorter measurement procedure (measurements are conducted simultaneously with pass-by noise measurements using the same multichannel equipment for data acquisition),

(ii) measurements which are performed under realistic loading condition of the track (under dynamic tram vehicle load),

(iii) better coherence of measured data than the measurements taken using standardized method [10], 

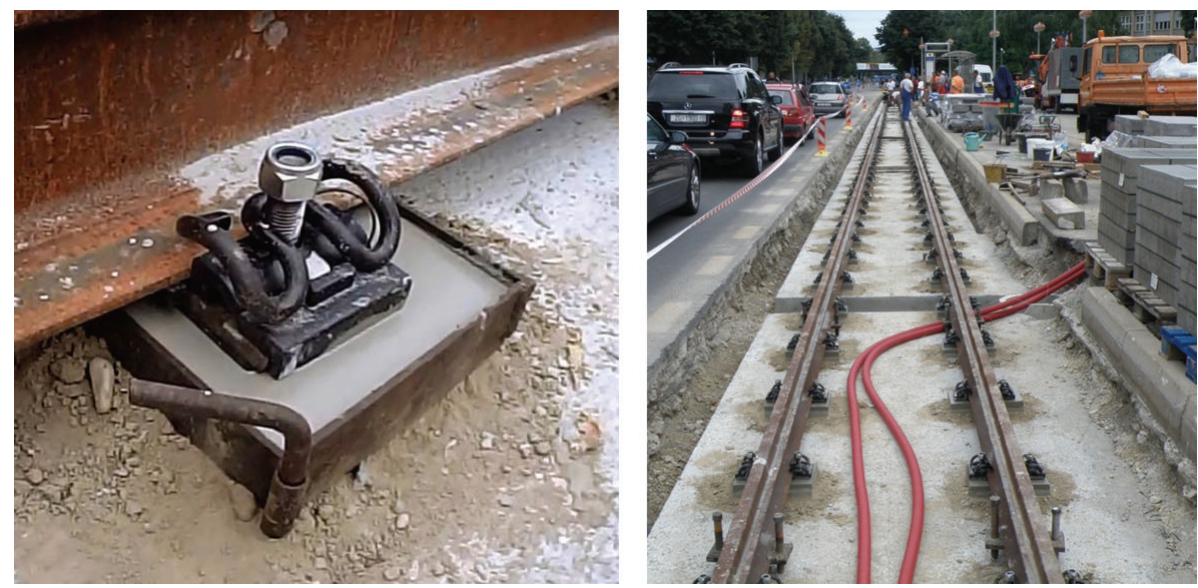

(a) Construction of the levelling layer with PPE fastenings and rail mounting
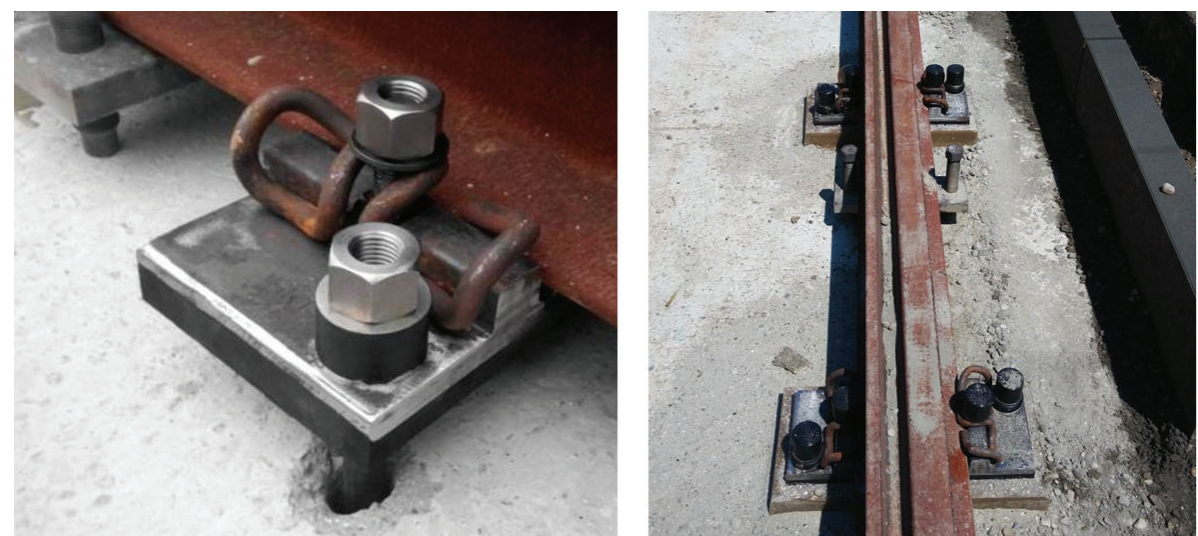

(b) Construction of the levelling layer with 21-CTT fastenings and rail mounting
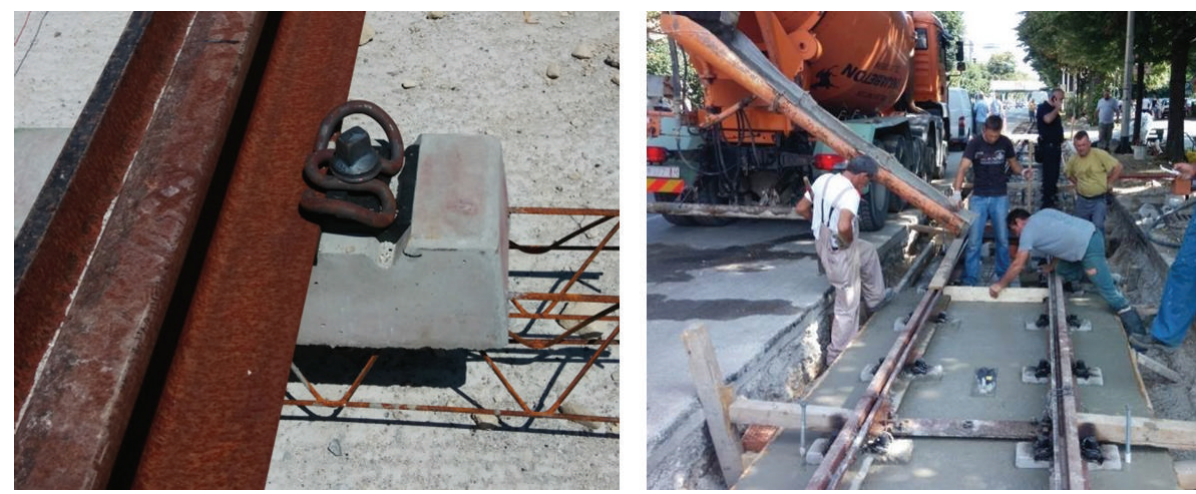

(c) Positioning of the sleepers with 21-STT fastenings, rail mounting, and construction of upper slab

Figure 7: Tram track superstructure construction on track subsections.

(iv) less equipment needed for conducting measurements (there is no need for instrumented hammer as vibrations are induced by passing vehicle),

(v) avoiding traffic closure and disruption on tram lane (measurements using hammer impact method require around 2 hours on track time, which would lead to partial traffic closure or a lot of measurement disruption due to passing rail and road vehicles on the test site), (vi) creating safer environment for operators conducting the measurements (apart from fixing the accelerometers to the rail, measurements can be made from the safe distance, further away from rail and road vehicles passing at the test sections).

4.1. Vibration Measurements Setup. Vibration measurements related to dynamic track properties are measured on rail foot and rail head in order to record accelerations in vertical and lateral direction. To conduct vibrations measurements 


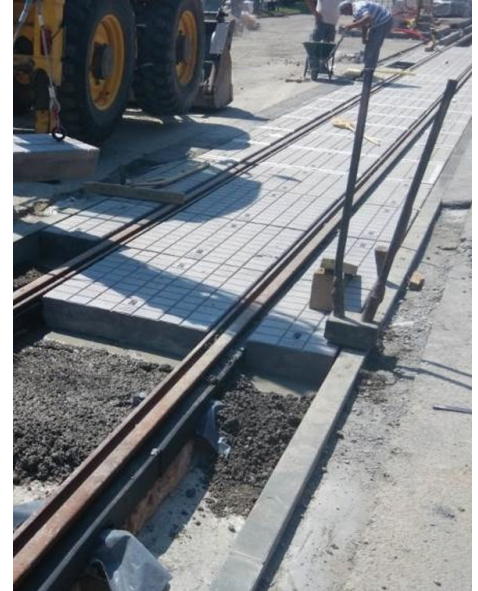

(a)

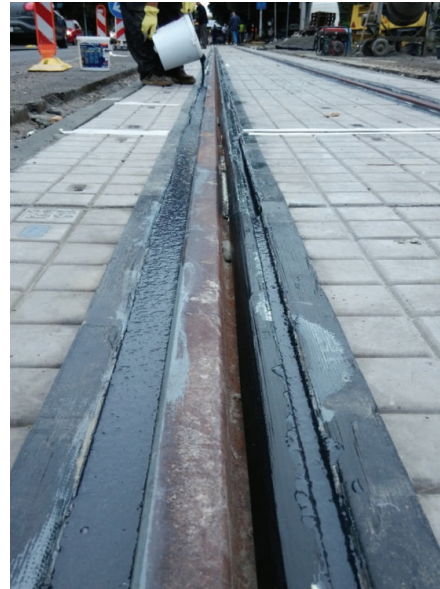

(b)

FIGURE 8: Embedding the tracks (a) and sealing the expansion joints (b).
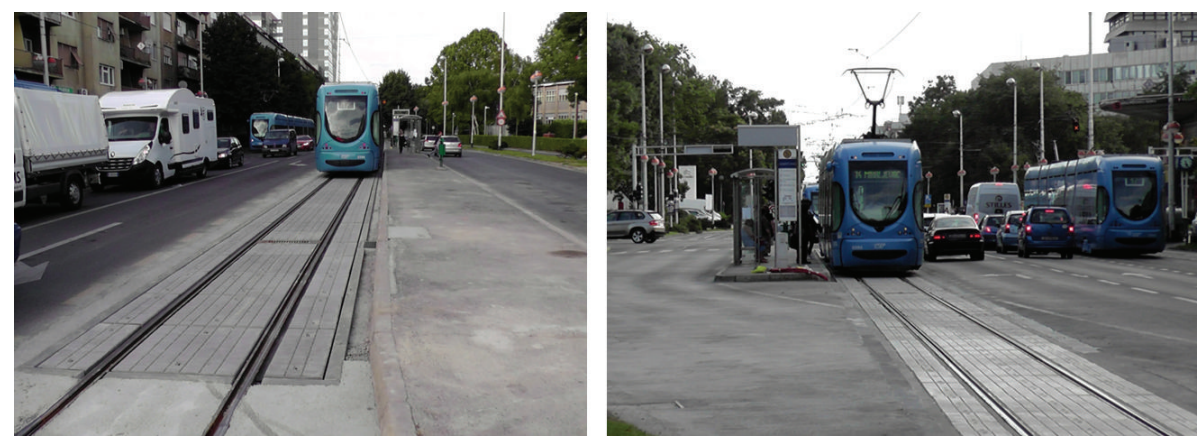

Figure 9: Test tram track section after the construction completion.

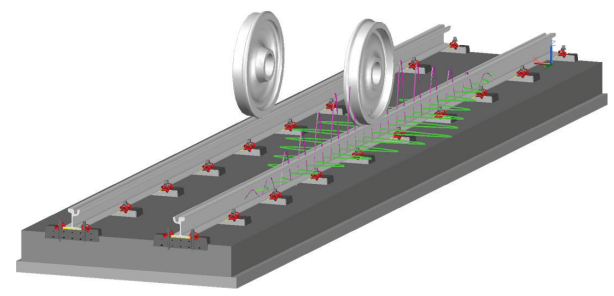

FIGURE 10: Representation of vertical and lateral vibration decay through the rail, from the excitation point.

at rail cross section, certain deviations from the procedures described in $[10,17]$ had to be made regarding the positioning and fixing of the accelerometers to the rail. Namely, measurement position in lateral direction had to be moved to the center of rail web instead of rail head, as described in the standards, due to track being embedded in lane shared with road vehicles (paved with RC plates as described in Section 3). For this reason, small revision shafts have been installed during construction of the track, providing the access to the rail foot and rail web for accelerometer positioning. Rail head outer side had to be sealed in order to create a gap-less surface for road vehicles, Figure 14, making it impossible to fix the third prescribed accelerometer.
Accelerometers used for conducting measurements are piezoelectric single directional Brüel and Kjær, type 4508B units with sensitivity of $100 \mathrm{mV} / \mathrm{G}$. They are fixed to the rail by means of magnets and linked to the data acquisition unit.

4.2. Noise Measurements Setup. Noise measurements have been conducted in accordance with [11] with the exeption of pass-by speed that has been limited to $30 \mathrm{~km} / \mathrm{h}$ (following the normal operational conditions on tram network in Zagreb) and the distance of microphone to the track axis. The distance of $2.5 \mathrm{~m}$ from track axis has been selected in order to reduce the influence of the surroundings (reflective and absorbing surfaces) that coud influence the noise propagation if standardized axis to microphone distance of $7.5 \mathrm{~m}$ has been used, Figure 12.

For conducting noise measurements microphones Brüel and Kjær (type 4189) able to record sound pressure in frequency range from $6.3 \mathrm{~Hz}$ to $20 \mathrm{kHz}$ have been used. Microphone wind guard has been used in order to eliminate the wind gust effect of a passing tram vehicles, Figure 15.

4.3. Data Acquisition. For successful determination of equivalent noise levels and track decay rates, measured quantities had to include 

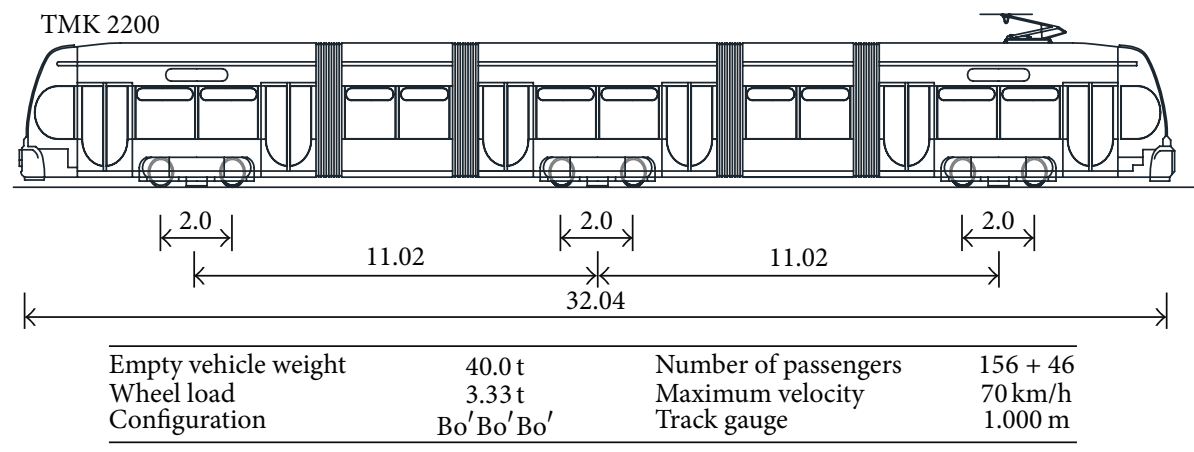

FIGURE 11: Tram type TMK 2200 used as a referent vehicle for pass-by measurements.

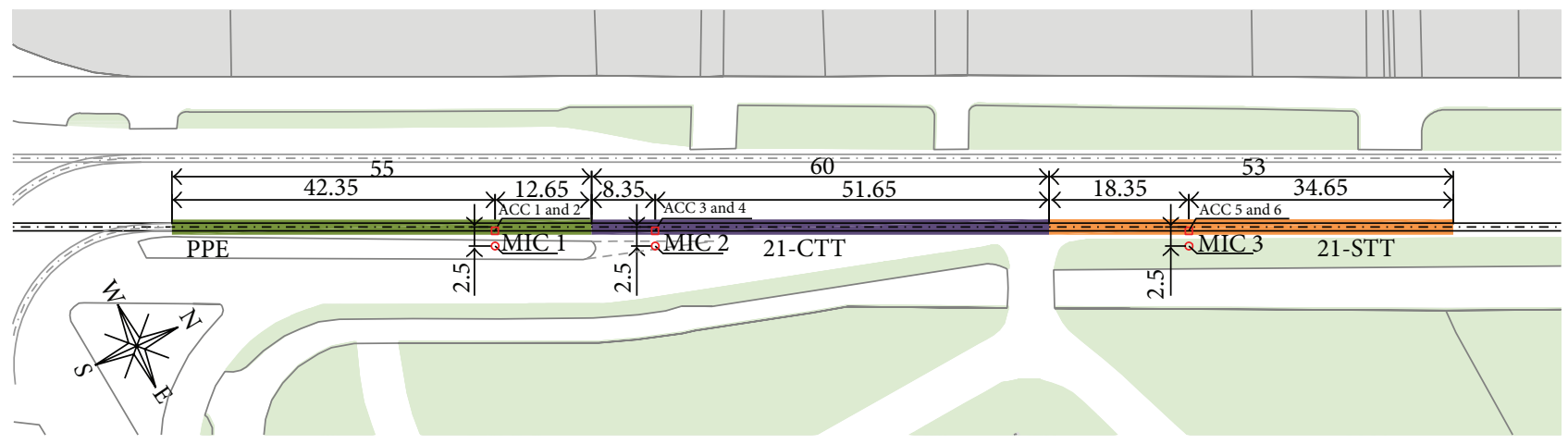

FIGURE 12: Test site layout with marked accelerometer (ACC) and microphone (MIC) positions.
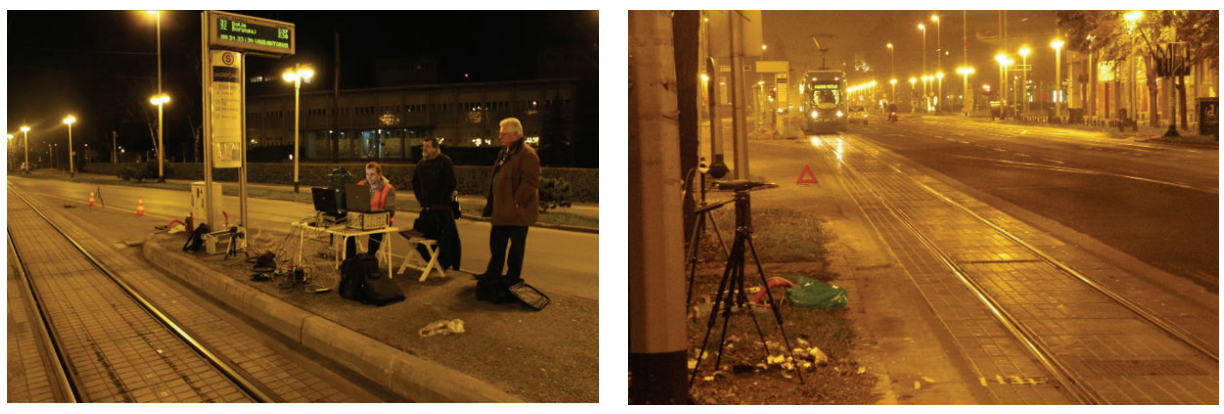

FIGURE 13: Conducting noise and vibration measurements under TMK 2266 pass-by at $30 \mathrm{~km} / \mathrm{h}$.

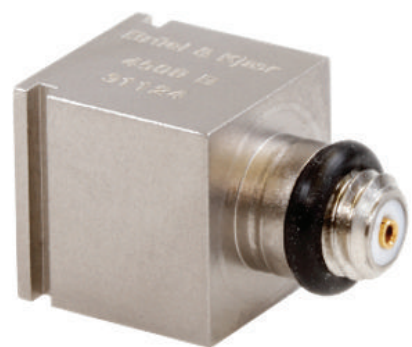

(a)

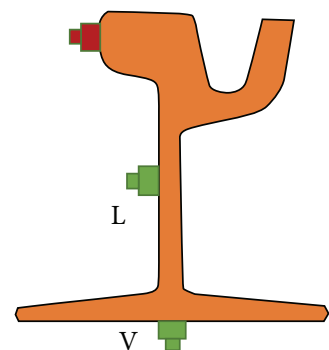

(b)

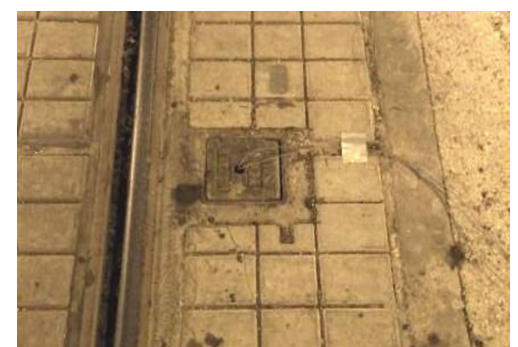

(c)

FIGURE 14: Accelerometer used for measurements (a); positions of accelerometers on grooved rail cross section: green indicates selected measuring positions in vertical and lateral direction and red indicates an accelerometer position proposed in [10], not applicable (b); revision shaft with accelerometers attached to the rail (c). 


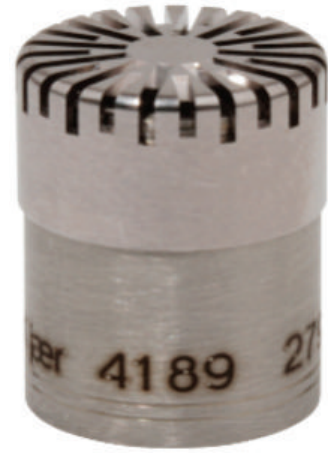

(a)

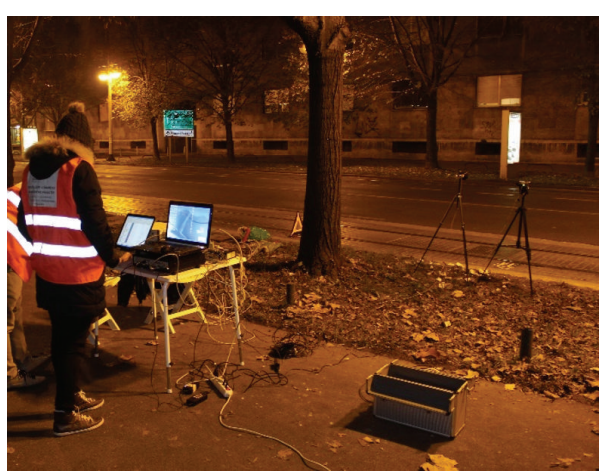

(b)

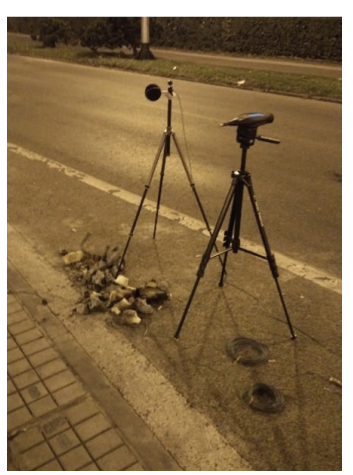

(c)

FIGURE 15: Microphone used for noise measurements (a); data acquisition and microphone positioning on different test sections (b and c).

(i) time record of rail accelerations $-a(t)\left[\mathrm{m} / \mathrm{s}^{2}\right]$,

(ii) time record of sound pressure level $-p(t)[\mathrm{Pa}]$,

(iii) vehicle pass-by time $-T_{p}[\mathrm{~s}]$,

(iv) vehicle speed $-v[\mathrm{~m} / \mathrm{s}]$.

Data acquisition of vibrations and sound pressure has been carried out using a Brüel and Kjær PULSE Analyzer using three input channels: two for vibrations and one for sound pressure. Data has been acquired using sampling frequency of $16.384 \mathrm{kHz}$. Noise levels have also been measured using a Brüel and Kjær sound level meter 2270 as a reference, Figure 13.

\section{Data Processing and Analysis}

All gathered vibrations and sound pressure time signals first had to be analyzed in time domain in order to identify vehicle axle positions. With known tram geometry and axel positions (Figure 11), exact vehicle speed and pass-by time could be derived based on the axel positions identified from raw acceleration signal in vertical direction (Figure 16). All vibrations and noise levels observed in frequency domain are then analyzed and presented in a third octave band of central frequencies between $f_{c}=100 \mathrm{~Hz}$ and $f_{c}=5000 \mathrm{~Hz}$.

\subsection{Vibration Analysis and Track Decay Rate Determination.} For determining track decay rates out of a time signal of rail accelerations, energy iteration approach has been applied. Namely, vibration decay through the rail can be estimated for each wheel, by fitting a slope to the curve of decaying vibration signal from the point of each wheel passing over the measuring position [28]. The influence of neighboring wheels has to be eliminated in order to achieve comparable results with standardized method [10]. Energy iteration method takes into account and eliminates the influence of neighboring wheels through 2 to 5 steps of iterations.

The basic assumption is that the vibration level decays exponentially from the point $x=0$, the point of vibration excitation (tram wheel):

$$
A(x) \approx A(0) e^{-\beta|x|} .
$$

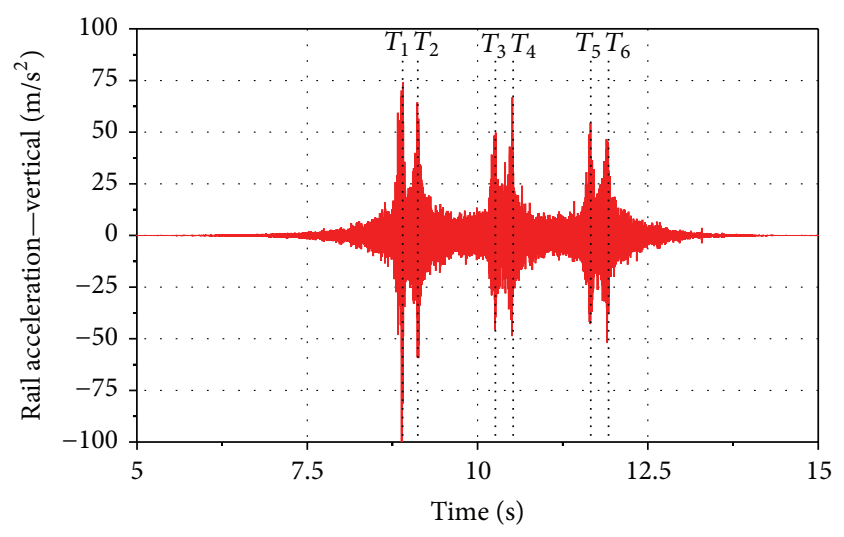

FIGURE 16: Determining axel positions out of a time signal of accelerations of a passing vehicle, where $T_{n}$ determines axel position in a time signal of rail accelerations.

$A(x)$ presents amplitude of vibrations along the rail, $A(0)$ presents the amplitude at the wheel-rail contact, and $\beta$ is the vibration decay exponent.

According to (1), decay rate can be given as

$$
\mathrm{TDR}=20 \log _{10}\left(e^{\beta}\right) \approx 8.686 \beta[\mathrm{dB} / \mathrm{m}]
$$

TDR can be derived from the ratio $R\left(f_{c}\right)$. This is the ratio of integrated vibration energy over length $L_{2}$, which includes the whole vehicle pass-by $\left(A_{\sum L_{2}}^{2}\left(f_{c}\right)\right)$ and the integrated vibration energy on short distance $L_{1}$ around the observed wheel $\left(A_{\sum L_{1}}^{2}\left(f_{c}\right)\right) . L_{1}$ is determined as a shortest distance between two axels of a vehicle which is in this case equal to $1.8 \mathrm{~m}$. Observed vibration length around the wheel is $-0.9 \mathrm{~m}$ to $+0.9 \mathrm{~m}$ from the wheel position, Figure 17:

$$
R\left(f_{c}\right)=\frac{A_{\sum L_{1}}^{2}\left(f_{c}\right)}{A_{\sum L_{2}}^{2}\left(f_{c}\right)} \approx 1-e^{-\beta L_{1}},
$$




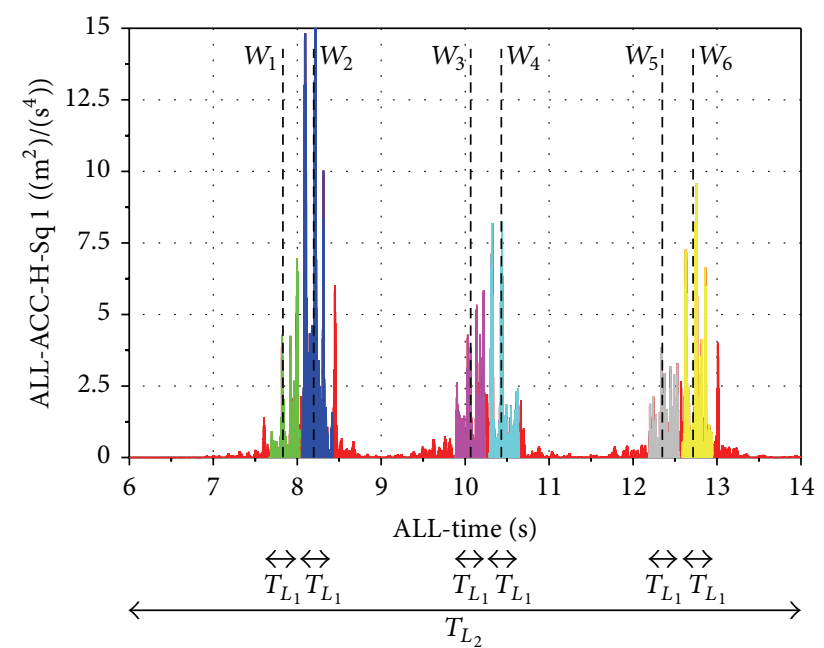

FIGURE 17: Squared vibrations of a tram TMK 2266 passing by $\left(f_{c}=\right.$ $100 \mathrm{~Hz}) . W_{1}$ to $W_{6}$ are wheel positions, $T_{L_{1}}$ is the integration time around the wheels, and $T_{L_{2}}$ is integration time over whole tram passing by.

where

$$
\begin{aligned}
A_{\sum L_{1}}^{2} & =\sum_{n=1}^{N} A_{n, L_{1}}^{2}=\sum_{n=1}^{N} \int_{-L_{1} / 2}^{L_{1} / 2}\left(A_{n}\left(x_{n}\right) e^{-\beta\left|x-x_{n}\right|}\right)^{2} d x \\
& =\frac{1-e^{\beta L_{1}}}{\beta} \sum_{n=1}^{N} A_{n}^{2}\left(x_{n}\right), \\
A_{\sum L_{2}}^{2} & =\sum_{n=1}^{N} \int_{L_{2}}\left(A_{n}\left(x_{n}\right) e^{-\beta\left|x-x_{n}\right|}\right)^{2} d x \\
& =\frac{1-e^{\beta L_{2}}}{\beta} \sum_{n=1}^{N} A_{n}^{2}\left(x_{n}\right) \approx \frac{1}{\beta} \sum_{n=1}^{N} A_{n}^{2}\left(x_{n}\right) .
\end{aligned}
$$

The approximation at the right-hand side in the above formula is valid for sufficiently large $L_{2}$, for example, a tram length.

The quantities $A_{\sum L_{1}}^{2}\left(f_{c}\right)$ and $A_{\sum L_{2}}^{2}\left(f_{c}\right)$ can be determined straightforwardly from measured acceleration signals. The transducer time signal is passed through third octave band pass filters resulting in a filtered time signal in range from $100 \mathrm{~Hz}$ to $5000 \mathrm{~Hz}$. Then, for each frequency band, the integrated squared vibration is determined over every wheel over length $L_{1}$, and for the whole pass-by for $L_{2}$. Using Formulae (3), (4), and (5) the vibration energy ratio $R\left(f_{c}\right)$ for each third octave frequency band is determined [17].

Time intervals $T_{L_{1}}$ that correspond to length $L_{1}$ contain mostly vibration energy of one wheel, but neighboring wheels also contribute to energy level, especially the wheels on the same bogie. $T_{L_{1}}$ is hence determined slightly shorter than the shortest distance between the axels on one bogie $(1.8 \mathrm{~m})$ in order to avoid energy overlapping.

From (2) and (3) track decay rate can be determined as

$$
\operatorname{TDR}\left(f_{c}\right)=-\frac{8.686}{L_{1}} \ln \left(1-R\left(f_{c}\right)\right) .
$$

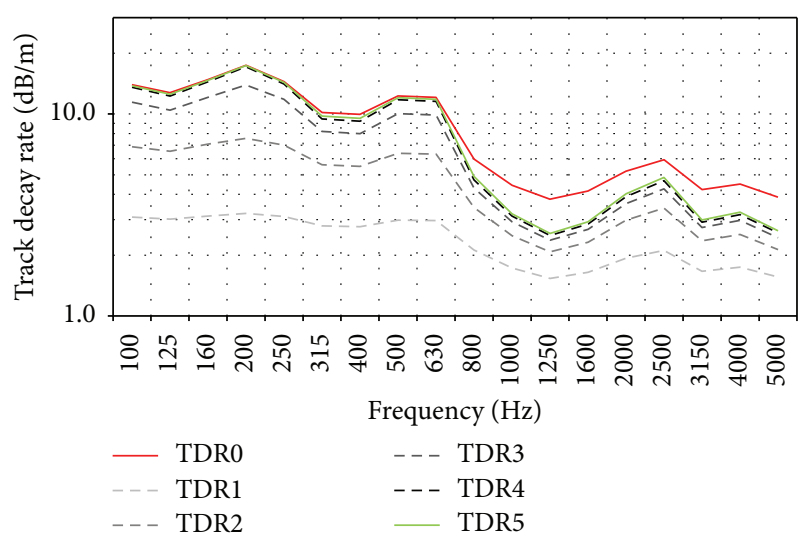

FIGURE 18: Example of determining track decay rate (TDR) in vertical direction using energy iteration method for a pass-by of a tram TMK 2266 on 21-STT section. Initially, measured level of decay rate is displayed in red and final value of decay rate after 5 steps of iterations in green.

To eliminate the influence of neighboring wheels, iteration procedure is used as follows [17]:

(i) A formula for estimating the decay exponent $\beta\left(f_{c}\right)$ at each band frequency is based on Formula (3), similar to Formula (5). The vibration energy ratio $R\left(f_{c}\right)$ is determined for the whole train pass-by as in Formula (3) and multiplied by $N / w_{k}\left(f_{c}\right)$, where $N$ is number of axles and $w_{k}\left(f_{c}\right)$ is weighting coefficient:

$$
\beta_{k}\left(f_{c}\right)=-\frac{\ln \left(1-R\left(f_{c}\right) N / w_{k}\left(f_{c}\right)\right)}{L_{1}} .
$$

A starting estimate for the initial decay exponent $\beta\left(f_{c}\right)$ is obtained with $w_{1}=2 N$. This initial condition assumes that half the vibration energy at each wheel transmits from other wheels.

(ii) The subsequent iterations are then calculated until the decay exponent $\beta\left(f_{c}\right)$ is stable to within $0.5 \mathrm{~dB}$, which is often achieved after four iteration steps $k=2$ to

$$
w_{k}\left(f_{c}\right)=\sum_{j=1}^{N} \sum_{i=1}^{N} e^{-2 \beta_{k-1}\left|x_{j}-x_{i}\right|},
$$

where $x_{j}-x_{i}$ is the distance between the current wheel $j$ and another wheel $i$.

The weighting coefficient $w_{k}$ represents a sum of the squared contributions from all wheels, viewed from each wheel and then summated over all wheels. If the decay exponent is large, the effect of adjacent wheels is small and $w_{k}$ quickly converges to $w_{k}=N$. If the decay is small, $w_{k}$ becomes larger. Sufficient convergence is often achieved within around five steps [17], Figure 18.

Using this method, decay rates on all three test subsections have been determined in vertical and lateral direction. Displayed results are averaged values of track decay rate (TDR) of 3 tram pass-bys. 


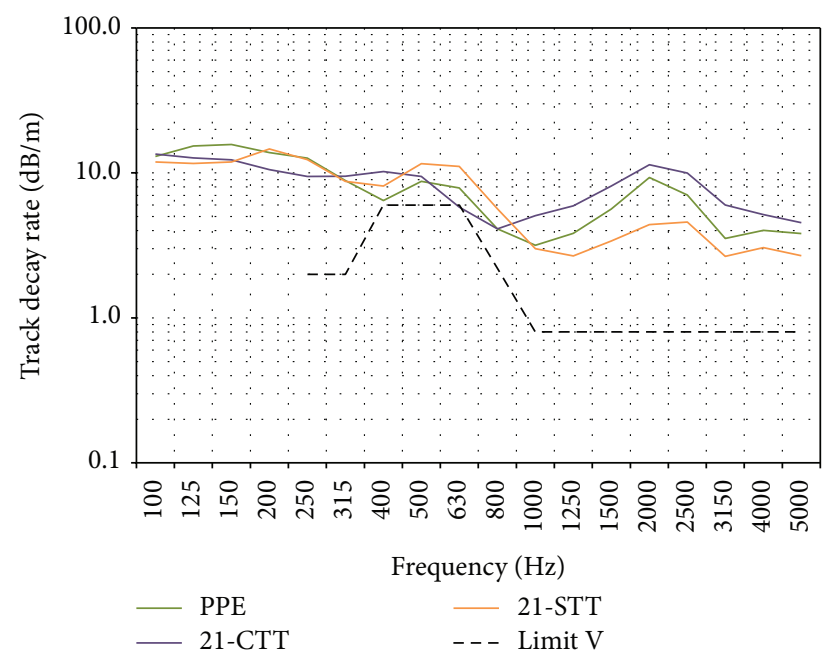

FIGURE 19: TDR in vertical direction on three test sections displayed along with lower limit proposed by [11].

It can be observed from Figure 19 that the vertical track decay rates are very similar on all three test sections in lower frequency range. In frequency range from $1000 \mathrm{~Hz}$ to $5000 \mathrm{~Hz}$ better performance of vibration attenuation is achieved by 21-CTT fastening system. 21-STT fastening system has the lowest TDR values, that is, less vibration attenuation due to its construction with only one elastic under-rail pad and overall stiffer slab track structure. Nevertheless, all three tested track constructions fulfill the standard prescribed lower limits, in both vertical and lateral directions.

Lateral track decay rates (Figure 20) are significantly higher than the limit values since the rail is embedded and sealed in a shared running surface of road vehicles, as described in Section 3.

5.2. Tram Pass-By Noise. As proposed by the European standards [11], time signals of sound pressure recorded during tram TMK 2266 pass-by have been expressed as sound pressure level in $\mathrm{dB}$ with the reference value $p_{0}=20 \mu \mathrm{Pa}$ :

$$
L_{p}=10 \log \left(\frac{p}{p_{0}}\right)^{2}[\mathrm{~dB}]
$$

Time signal of sound pressure levels has to be recorded in minimal length $T_{\text {rec }}$ which corresponds to $L_{p A e q, 125 \mathrm{~ms}}$ level that is at least $10 \mathrm{~dB}$ lower than sound pressure levels in front of and after the vehicle (Figure 21).

Measurement time interval $T_{p}$ corresponds to total tram length which is used for calculation of equivalent sound pressure level of a passing vehicle $\left(L_{p A e q, T_{p}}\right)$ according to

$$
L_{p A e q, T_{p}}=10 \log \left(\frac{1}{T_{p}} \int_{0}^{T_{p}} \frac{p_{A}^{2}(t)}{p_{0}^{2}}\right)[\mathrm{dB}]
$$

where $L_{p A e q, T_{p}}$ is the $A$-weighted equivalent continuous sound pressure level in $\mathrm{dB} ; T_{p}$ is the measurement time interval in $s ; p_{A}(t)$ is the $A$-weighted instantaneous sound

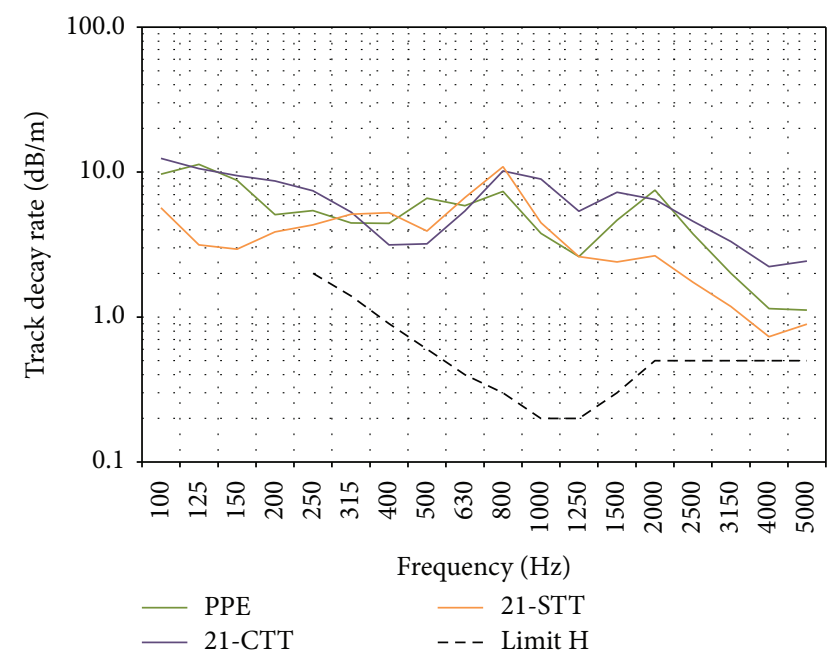

FIGURE 20: TDR in lateral direction on three test sections displayed along with lower limit proposed by [11].

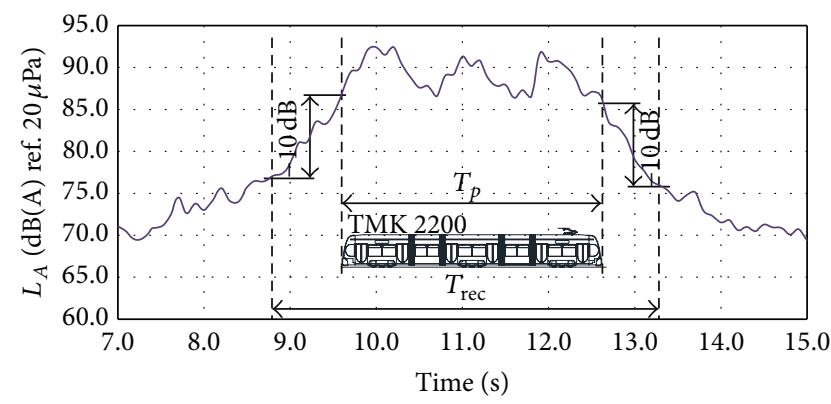

FIGURE 21: Sound pressure level during tram TMK 2266 passing by on $21-\mathrm{CTT}$ section at $30 \mathrm{~km} / \mathrm{h} ; T_{p}$ represents a measurement time interval of a whole vehicle pass-by and $T_{\text {rec }}$ minimal recorded time interval.

TABLE 1: Equivalent noise levels of tram TMK 2266 at $30 \mathrm{~km} / \mathrm{h}$ for all test sections with standard deviation of measured results.

\begin{tabular}{lcc}
\hline Test section & $L_{p \text { Aeq, } T_{p}}[\mathrm{~dB}]$ & $\mathrm{SD}$ \\
\hline PPE & 84.5 & 0.3 \\
21-CTT & 80.9 & 1.4 \\
21-STT & 82.9 & 0.8 \\
\hline
\end{tabular}

pressure at running time $t$ in $\mathrm{Pa}$; and $p_{0}$ is the reference sound pressure $\left(p_{0}=20 \mu \mathrm{Pa}\right)$.

Recorded sound pressure levels of 2 pass-bys at each test subsection have been recorded for tram TMK 2266 pass-by at $30 \mathrm{~km} / \mathrm{h}$ and the average value is expressed as final equivalent noise level, Table 1.

It can be observed that the same referent vehicle at constant speed of $30 \mathrm{~km} / \mathrm{h}$ emits different noise levels at different track sections. Lowest noise levels are recorded at 21CTT test section that also corresponds to highest track decay rate measurements. At reference test section, PPE, highest noise levels are recorded (up to $3.6 \mathrm{~dB}$ higher than 21-CTT and $1.6 \mathrm{~dB}$ higher than on 21-STT subsection). 


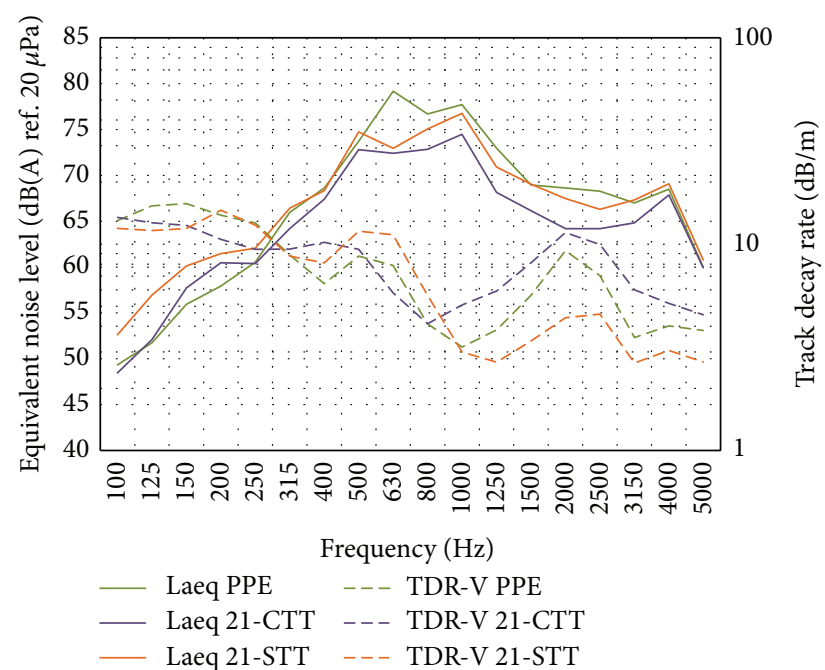

FIGURE 22: Spectral representation of equivalent noise levels on test subsections with respect to track decay rates in vertical direction.

In order to assess the influence of track-side contribution to the equivalent noise levels of a passing vehicle at all test subsections, spectral analysis of noise levels has been conducted in the same frequency range as track decay rates, $100 \mathrm{~Hz}$ to $5000 \mathrm{~Hz}$, in $1 / 3$ octave bands, Figure 22 . Vertical decay rate has been selected for further analysis, since it was concluded that the horizontal decay rate is much higher due to rail being embedded in the road surface and had much lower effect on the noise emissions. It can be clearly observed that the tram pass-by at $30 \mathrm{~km} / \mathrm{h}$ emits highest noise levels in the $500 \mathrm{~Hz}$ to $1000 \mathrm{~Hz}$ frequency range. It has been observed that there is a correlation between lower noise levels and higher track decay rates on all three subsections, especially in $1000 \mathrm{~Hz}$ to $3150 \mathrm{~Hz}$ frequency range. In this particular range, highest track decay rate values clearly contribute to lowest noise levels on 21-CTT subsection. This indicates higher decay rate of the track which still contributes to lower noise of vehicle pass-bys although the requirement by EN ISO 3095 [11] has been met on all subsections, Figure 22. Since rolling noise is not the only contributing factor to overall noise levels, engine noise and other noise sources can also affect equivalent noise level difference between subsections.

\section{Conclusion}

Due to high traffic loads, tram tracks in the City of Zagreb are exposed to high stresses; they rapidly degrade and deteriorate. To answer the harsh tram traffic operation conditions and to optimize maintenance procedures, two new solutions for rail fastening systems were developed, named 21-CTT 21-STT systems. The main objective in developing the new systems was to develop a tram track structure which would be quick and simple to construct, have longer exploitation life, be easy to maintain, and have good exploitation characteristics. Exploitation characteristics of the developed systems were investigated on the test tram track and compared with a reference track built with commonly used PPE fastening
TABLE 2: Comparison of the characteristics of the surveyed tramway track constructions.

\begin{tabular}{lcc}
\hline Characteristic & \multicolumn{2}{c}{ System } \\
& 21-CTT & 21-STT \\
\hline Construction/installation speed & $=$ & + \\
Construction/installation cost & + & ++ \\
Stray current protection & ++ & + \\
Maintenance & $=$ & + \\
Exploitation life & + & ++ \\
Vibration attenuation & + & - \\
Noise attenuation & ++ & +
\end{tabular}

=: similar to reference PPE track, + : better than reference PPE track, ++: significantly better than reference PPE track, and -: worse than PPE reference track.

system. Table 2 gives a summary of the characteristics of the surveyed track structures.

The experience gained during the construction of test subsection and measurement results led to the following conclusions:

(i) 21-CTT represents an upgrade of existing rail fastening solutions. For its creation, standard rail track material and elements were used. Due to their serial production, this system can be constructed for much lower market price. By vulcanization of certain parts of the fastening system, tram track is isolated and becomes resistant to the occurrence of stray currents.

(ii) 21-STT is a new concept for construction of the tram track structures in Croatia. It is characterized by very high resistance and low deformation under traffic load and good stress distribution through the track structure. It is created by using standard elements of conventional rail tracks, its installation is fast and simple, and its maintenance is easy.

(iii) By measuring the vibration of track test constructions and comparing them to reference values recorded on reference PPE subsection, it was found that there is an increase in the overall level of vibration on subsection 21-STT (caused by the greater stiffness of track structure), and small reduction of vibration levels at the test subsection 21-CTT.

(iv) The effect of vibrations on the track noise attenuation has been observed by determining track decay rate. All three test track subsections are within the standard prescribed value. It was observed that both new systems have better vibration damping ability at higher frequencies and that they behave very well in terms of low noise emission.

(v) Results of measuring track decay rate have been confirmed by measurements of tram pass-by noise. At reference test track subsection, PPE, highest noise levels are recorded (up to $3.6 \mathrm{~dB}$ higher than 21-CTT and $1.6 \mathrm{~dB}$ higher than on 21-STT subsection).

(vi) 21-CTT makes a commercially cost-effective alternative to existing rail fastening solutions, while meeting 
all the requirements of a modern tram track structure. Such a system is the optimal solution for the tram track superstructure reconstructions.

(vii) 21-STT is the optimal choice for the construction of new and reconstruction of existing tram tracks, when the (re)construction project anticipates the construction of new track substructure.

\section{Competing Interests}

The authors declare that they have no competing interests.

\section{Acknowledgments}

This work was supported by the Ministry of Science, Education and Sports of the Republic of Croatia within the framework of the Scientific Project "Noise and Vibrations on Tram and Railway Tracks" (Grant no. 082-0000000-2185). The authors would also like to express sincere gratitude to the ZG Holding d.o.o., ZET, Edilon)(Sedra HmbH, Beton Lučko d.o.o., DIV Group d.o.o. Gumiimpex-GRP d.d., Georad d.o.o., and PGP d.o.o. for the financial and technological support given to this study.

\section{References}

[1] M. Ahac, Mechanistic-empirical model for tram track gauge deterioration during exploitation [Ph.D. thesis], University of Zagreb Faculty of Civil Engineering, 2013.

[2] M. Tomičič-Torlakovič, G. Ćirović, S. Mitrović, and V. Branković, "Optimisation and ranking of permanent way types for light rail systems," Gradjevinar, vol. 66, no. 10, pp. 917-927, 2014.

[3] S. Jovanović, H. Guler, and B. Čoko, "Track degradation analysis in the scope of railway infrastructure maintenance management systems," Gradjevinar, vol. 67, no. 3, pp. 247-258, 2015.

[4] S. Lakušić, V. Tkalčević Lakušić, and M. Bogut, "Protection of historical buildings from rail traffic vibrations," in Protection of Historical Buildings, pp. 1399-1406, CRC Press/Balkema, Taylor \& Francis Group, Rome, Italy, 2009.

[5] I. Haladin, S. Lakusic, and M. Bogut, "Analysis of tram traffic vibrations in respect to tram track structure and exploitation period," in Proceedings of the 20th International Congress on Sound and Vibration (ICSV '13), pp. 3242-3249, International Institute of Acoustics and Vibration, Bangkok, Thailand, July 2013.

[6] S. Lakušić, I. Haladin, and M. Bogut, "Analysis of tram induced vibration influence on underground garage structure through exploitation," in Proceedings of the 21st International Congress on Sound and Vibration, pp. 13-17, International Institute of Acoustics and Vibration, Beijing, China, July 2014.

[7] S. Lakušić, Dynamic behaviour of the tram-track interaction [Doctoral thesis], University of Zagreb Faculty of Civil Engineering, Zagreb, Croatia, 2003.

[8] E. Curić, D. Drenić, and Z. Grdić, "Analysis of carrying capacity of concrete sleepers for switches and crossings under static and dynamic load," Gradjevinar, vol. 66, no. 12, pp. 1117-1124, 2014.

[9] S. Lakušić, I. Haladin, and J. Košćak, "Monitoring report on tram track fastening system Zagreb 21-CTT and Zagreb 21-STT on Savska Street in Zagreb," Tech. Rep., Zagreb Municipality Transit System (ZET); University of Zagreb Faculty of Civil Engineering, Zagreb, Croatia, 2015.

[10] HRN, "Railway applications-noise emission-characterisation of the dynamic properties of track sections for pass by noise measurements," HRN EN 15461:2011, 2011, (HRN EN 15461:2008+A1:2010).

[11] HRN EN ISO, "Acoustics—railway applications-measurement of noise emitted by railbound vehicles," ISO 3095, 2013.

[12] B. Hemsworth, "STAIRRS—strategies and tools to assess and implement noise reducing measures for railway systems," Final Technical Report, 2003.

[13] C. Esveld, Modern Railway Track, TU Delft, Delft, Netherlands, 2nd edition, 2001.

[14] D. J. Thompson and C. J. C. Jones, "A review of the modelling of wheel/rail noise generation," Journal of Sound and Vibration, vol. 231, no. 3, pp. 519-536, 2000.

[15] C. J. C. Jones, D. J. Thompson, and R. J. Diehl, “The use of decay rates to analyse the performance of railway track in rolling noise generation," Journal of Sound and Vibration, vol. 293, no. 3-5, pp. 485-495, 2006.

[16] M. H. A. Janssens, M. G. Dittrich, F. G. de Beer, and C. J. C. Jones, "Railway noise measurement method for pass-by noise, total effective roughness, transfer functions and track spatial decay," Journal of Sound and Vibration, vol. 293, no. 3-5, pp. 1007-1028, 2006.

[17] FprCEN/TR 16891, "Railway applications-acousticsmeasurement method for combined roughness, track decay rates and transfer functions," Tech. Rep. CEN/TC 256, Institute for Standardization of Serbia, 2016.

[18] B. Betgen, P. Bouvet, G. Squicciarini, and D. J. Thompson, "The STARDAMP Software: an assessment tool for wheel and rail damper efficiency a few words on rolling noise the principles of rail and wheel dampers," in Proceedings of the AIA-DAGA 2013 Conference on Acoustics, p. 4, Merano, Italy, 2013.

[19] J. Maes and H. Sol, "A double tuned rail damper-increased damping at the two first pinned-pinned frequencies," Journal of Sound and Vibration, vol. 267, no. 3, pp. 721-737, 2003.

[20] D. J. Thompson, C. J. C. Jones, T. P. Waters, and D. Farrington, "A tuned damping device for reducing noise from railway track," Applied Acoustics, vol. 68, no. 1, pp. 43-57, 2007.

[21] Commission Regulation (EU) No 1304/2014 of 26 November 2014 on the technical specification for interoperability relating to the subsystem 'rolling stock-noise', Official Journal of the European Union, p. 17, 2014, http://eur-lex.europa.eu/ legal-content/EN/TXT/?uri=CELEX:32014R1304.

[22] "Railway applications-noise emission-rail roughness measurement related to rolling noise generation," HRN EN 15610:2009, 2009.

[23] M. G. Dittrich, F. Létourneaux, and H. Dupuis, "Background for an new standard on pass-by measurement of combined roughness, track decay rate and vibroacoustic transfer functions," in Noise and Vibration Mitigation for Rail Transportation Systems, vol. 126, pp. 197-204, Springer, Berlin, Germany, 2013.

[24] W. Li, J. Jiang, R. Dwight, and C. Schulten, "An investigation of a method for track decay rate measurement using train pass-bys," in Proceedings of the Australian Acoustical Society Conference 2011: Breaking New Ground, Acoustics 2011, no 75, pp. 563-568, Gold Coast, Austraila, November 2011.

[25] M. G. Dittrich, "Procedure and applications of combined wheel/rail roughness measurement," in Proceedings of the 
NAG/DAGA International Conference on Acoustics, pp. 2-4, Rotterdam, Netherlands, March 2009.

[26] M. G. Dittrich, "Track decay rate measurement using the PBA technique," in Proceedings of the Euronoise 2006, Tampere,Finland, 2006.

[27] M. T. Kalivoda, "Track decay rate of different railway noise test sites," in Forum Acusticum, p. 3, Budapest, Hungary, 2005.

[28] M. Wirnsberger, M. G. Dittrich, J. Lub et al., "Methodologies and actions for rail noise and vibration control," METARAIL Project Final Report for Publication, 1999. 


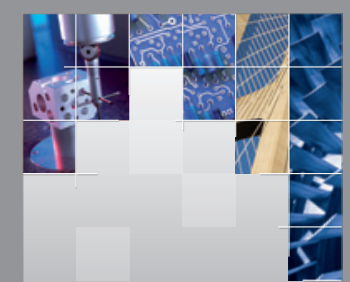

\section{Enfincering}
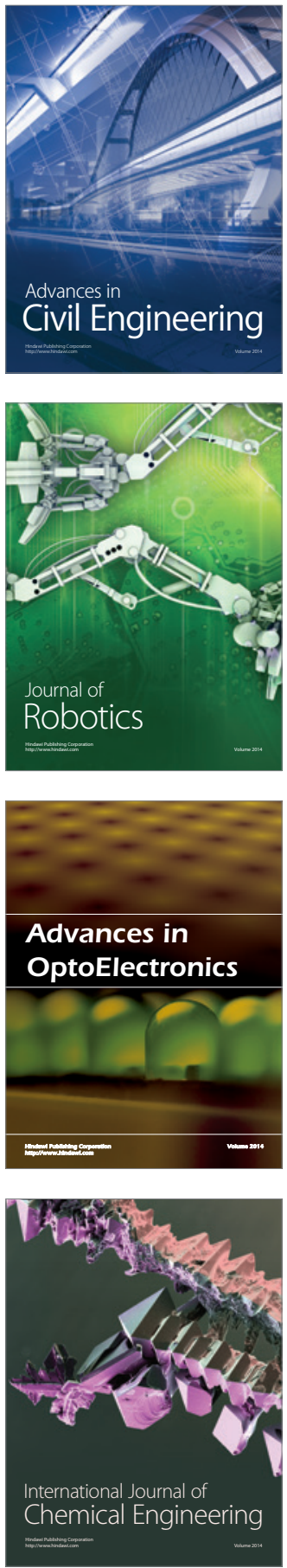

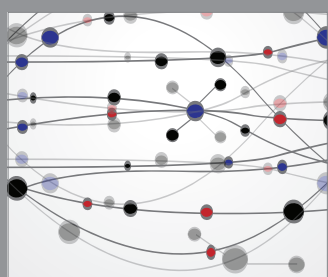

The Scientific World Journal

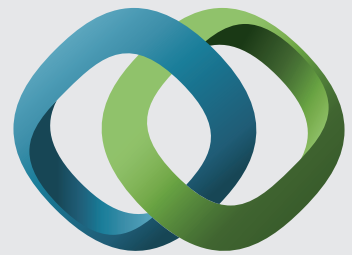

\section{Hindawi}

Submit your manuscripts at

http://www.hindawi.com
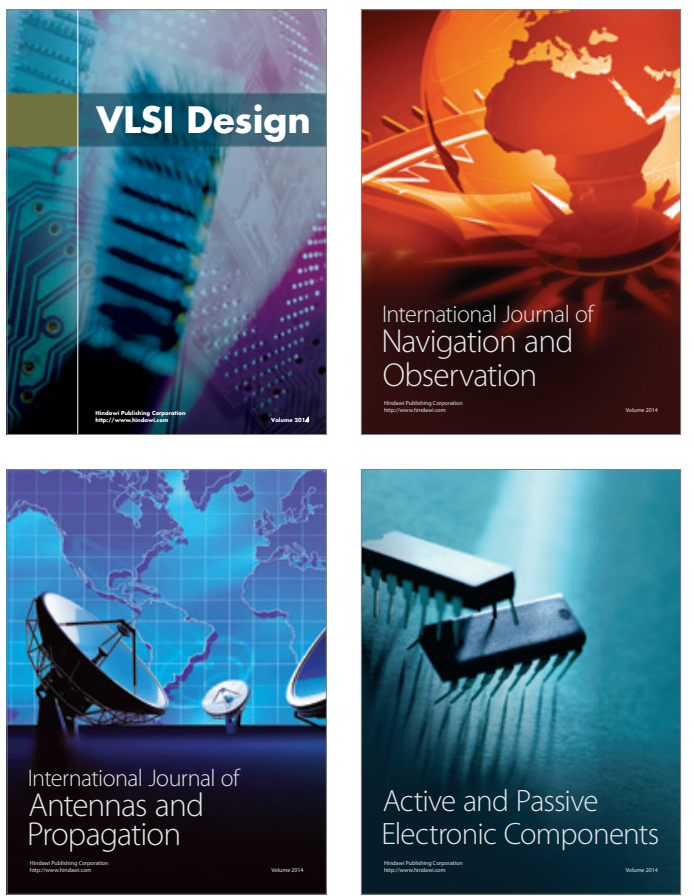
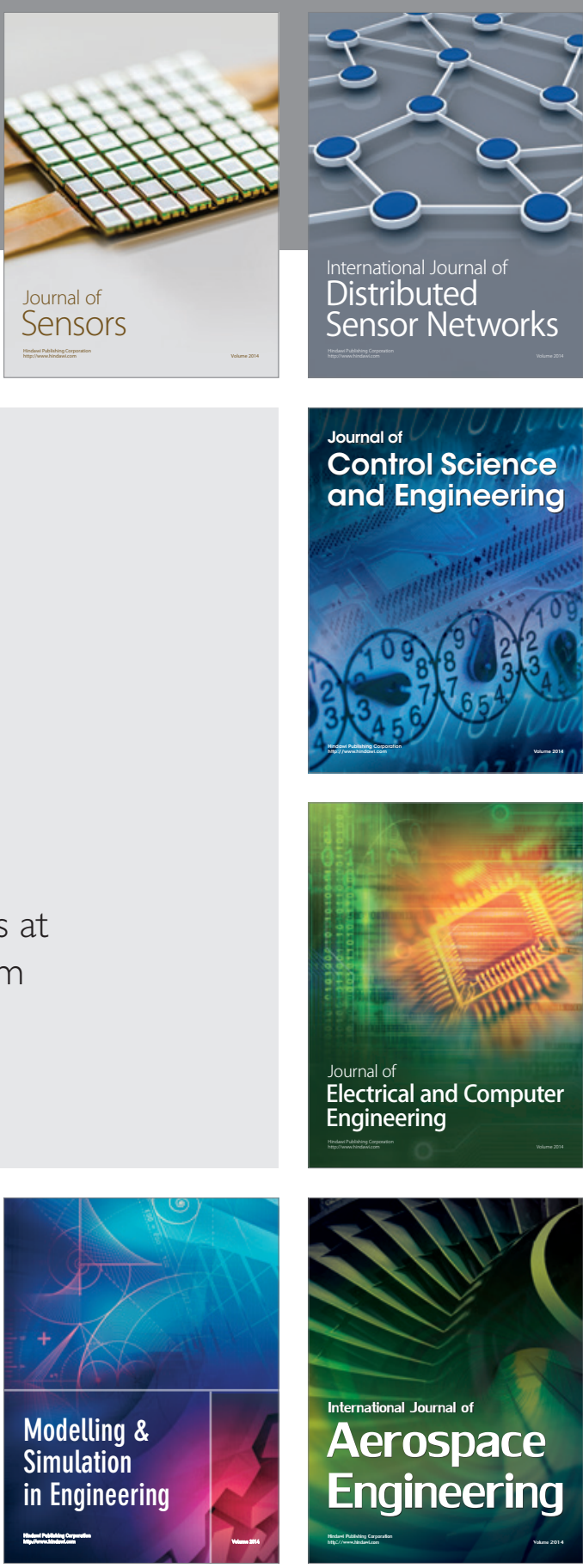

International Journal of

Distributed

Sensor Networks

Journal of

Control Science

and Engineering
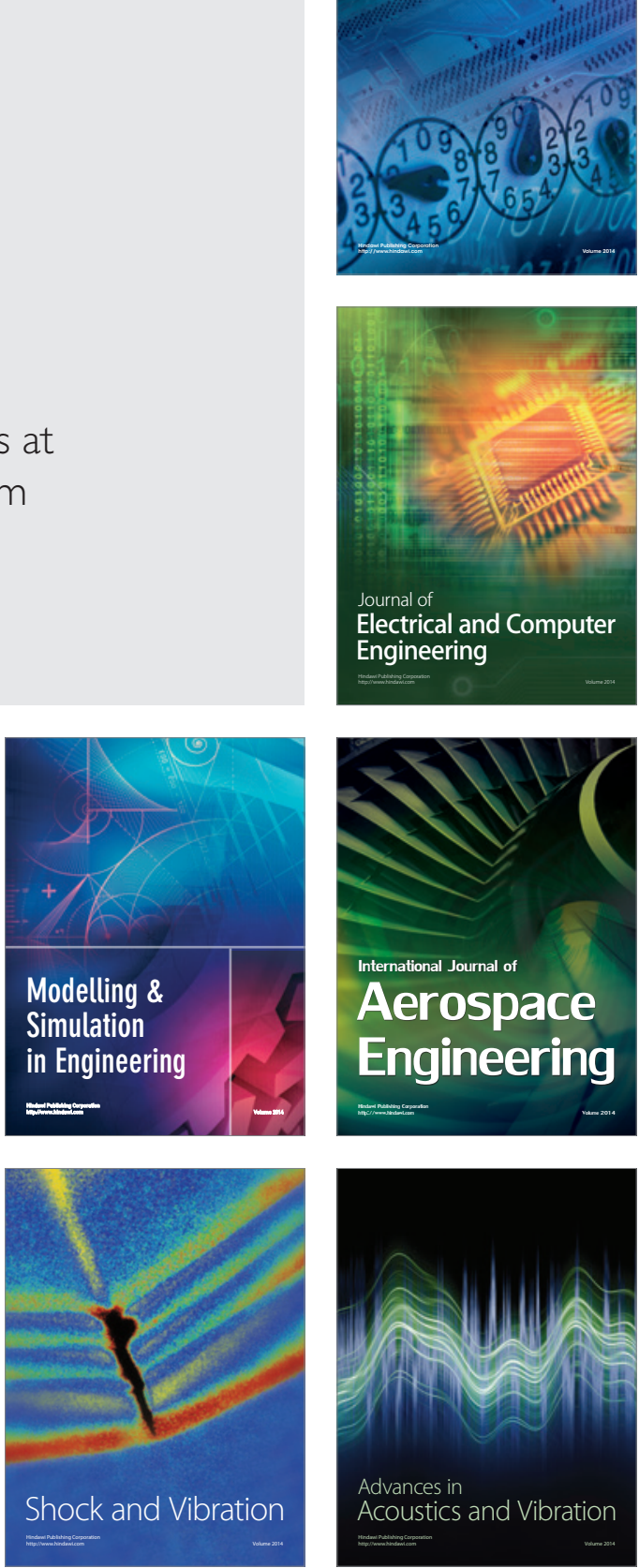